\title{
Is severe COVID-19 pneumonia a typical or atypical form of ARDS? And does it matter?
}

\author{
Ewan C. Goligher ${ }^{1,2,3}$ (]) V. Marco Ranieri ${ }^{4}$ and Arthur S. Slutsky ${ }^{1,5^{*}}$ (B)
}

๑ 2020 Springer-Verlag GmbH Germany, part of Springer Nature

The coronavirus disease 2019 (COVID-19) pandemic has proven remarkable for many reasons, among them its capacity to provoke controversy and debate. One hotly debated question is whether severe COVID-19 pneumonia should be classified simply as another cause of acute respiratory distress syndrome (ARDS), or as a particular subtype of ARDS with pathophysiological features so unique that a different approach to ventilatory management is needed. Does severe COVID-19 pneumonia fall within the usual pathophysiological spectrum of ARDS or is it a qualitatively different disease state? And what consequences might the answer to this question hold for the optimal ventilatory management of severe COVID-19?

In a recent article, Chiumello et al. approach these questions by comparing the respiratory pathophysiological features of patients with early COVID-19 ARDS to historical controls with classical (non-COVID-19) ARDS [1]. A hallmark of classical ARDS is that hypoxemia results predominantly from atelectasis and consolidation, with a consequent increase in physiological shunt fraction $[2,3]$. In the matched cohort study, Chiumello et al. demonstrated exactly this in patients with classical ARDS: both venous admixture and hypoxemia $\left(\mathrm{PaO}_{2} /\right.$ $\mathrm{FiO}_{2}$ ratio) were correlated to the fraction of non-aerated lung. In their patients with COVID-19 pneumonia, by contrast, they found that venous admixture and $\mathrm{PaO}_{2} /$ $\mathrm{FiO}_{2}$ were not correlated to the fraction of non-aerated lung, suggesting a different mechanism of hypoxemia. Moreover, the severity of hypoxemia appeared to be out of proportion to the impairment in lung mechanics.

\footnotetext{
*Correspondence: arthur.slutsky@unityhealth.to

${ }^{5}$ Keenan Centre for Biomedical Research, Li Ka Shing Knowledge Institute, St. Michael's Hospital, 30 Bond Street, Toronto, ON M5B 1W8, Canada

Full author information is available at the end of the article
}

When matched on compliance, patients with COVID-19 ARDS had more severe hypoxemia; and when matched on hypoxemia, they had relatively preserved compliance compared to patients with classical ARDS. The authors concluded that COVID-19 ARDS should be regarded as an "atypical subset of ARDS."

These conclusions accord with the pathological findings revealing unusual involvement of the pulmonary microvasculature and associated coagulopathy [4, 5]. As Chiumello et al. point out, patients in their COVID19 ARDS cohort seem to have strikingly "vasocentric" disease compared to classical ARDS (although the pulmonary microcirculation is clearly affected in classical ARDS as well). Computational models of deranged pulmonary microcirculatory function have been able to reproduce the depth of hypoxemia observed in COVID19 ARDS in the absence of significant pure shunt [6].

Nevertheless, before generalizing the results of Chiumello et al. it's important to note that the sample size studied was very small $(n=32)$. Crucially, it seems doubtful that the patients enrolled in the study by Chiumello et al. are typical of COVID-19 ARDS patients more generally. In their cohort, the median compliance was $50 \mathrm{ml} / \mathrm{cmH}_{2} \mathrm{O}$, a value substantially higher than generally observed in recent studies of COVID-19 ARDS which have reported median values for static compliance that are considerably lower: $27 \mathrm{~mL} / \mathrm{cmH}_{2} \mathrm{O}(n=257)$ [7], $28 \mathrm{~mL} / \mathrm{cmH}_{2} \mathrm{O}(n=267)$ [8], $35 \mathrm{~mL} / \mathrm{cmH}_{2} \mathrm{O} \quad(n=296)$ [9], $41 \mathrm{~mL} / \mathrm{cmH}_{2} \mathrm{O}(n=301)$ [10], and $32 \mathrm{ml} / \mathrm{cmH}_{2} \mathrm{O}$ $(n=533)$ [11], similar to values in patients with classical ARDS [12] (Fig. 1). The differences between the 32 patients and these results (total $n=1654$ ) cannot be explained by the timing of the Crs measurements since these values were also obtained at baseline. These differences also cannot be explained by differences in the level of positive end-expiratory pressure (PEEP) at which compliance was measured $\left(5 \mathrm{cmH}_{2} \mathrm{O}\right.$, in Chiumello's study;

\section{Springer}




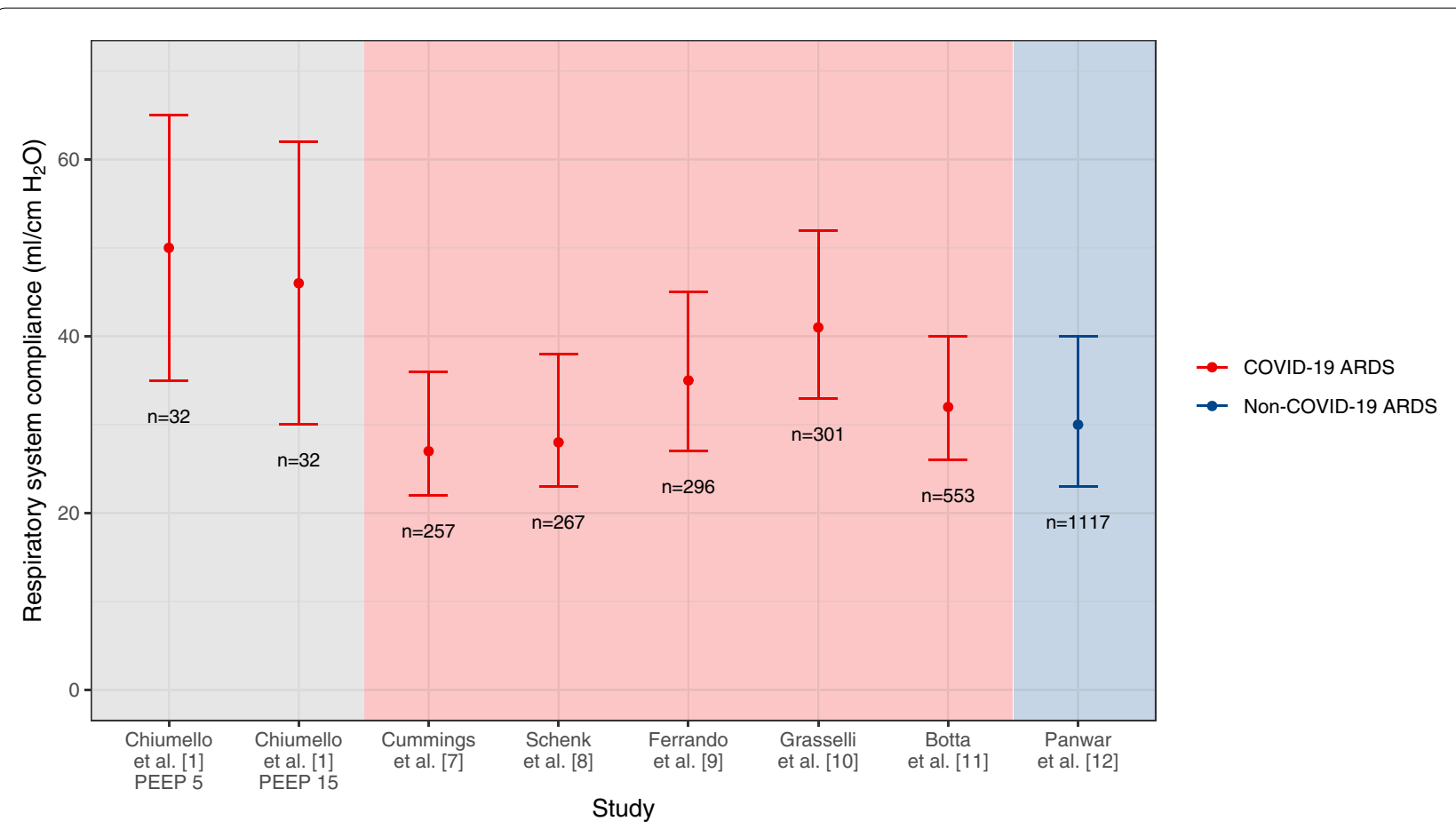

Fig. 1 Distribution of respiratory system compliance in the study of COVID-19 ARDS reported by Chiumello et al. in other studies of COVID-19 ARDS, and in non-COVID-19 ARDS. Error bars represent standard deviations (for Chiumello et al.) or interquartile ranges (for all other studies)

"clinical values of PEEP" in the other studies) since when Chiumello increased PEEP to $15 \mathrm{cmH}_{2} \mathrm{O}$, the median Crs was approximately $46 \mathrm{ml} / \mathrm{cmH}_{2} \mathrm{O}$, still substantially higher than the $>1600$ COVID-19 patients from the other studies. We might therefore regard the patients in the study by Chiumello et al. as an "atypical subset of COVID-19 ARDS."

In any case, we may ask, "So what?" even if COVID19 ARDS were an atypical subset of ARDS (and it's not clear that this is indeed the case), should this prompt any changes to management? The "vasocentric" pathophysiology demonstrated in this and many other studies suggests a potential role for vascular interventions such as therapeutic anticoagulation [13]; relevant clinical trials are ongoing. An important question is whether the findings of this study suggest any changes in ventilatory management. Chiumello et al. contend that their findings argue against the use of a "higher" PEEP ventilation strategy in the early phase of COVID19 ARDS. In their study, hypoxemia was not primarily the consequence of atelectasis and increases in PEEP were associated with signs of overdistention (reduced compliance, unchanged/worsened dead space) despite a substantial improvement in oxygenation. Unfortunately, they did not directly quantify the degree of lung recruitment by CT scan. Other studies in COVID-19
ARDS have reported varying degrees of lung recruitability $[14,15]$. The lower compliance observed in the patients from the other studies suggests (Fig. 1) that many patients with COVID-19 ARDS may have substantial potential for lung recruitment.

It is widely appreciated that ARDS is a heterogeneous disorder and that many patients with ARDS may have little or no potential for lung recruitment [16-18]. Higher PEEP may well be harmful in such patients whether or not they have COVID-19 [19]. The findings of Chiumello et al. should alert clinicians to the fact that, given the pulmonary vascular dysfunction associated with COVID-19 ARDS, a positive oxygenation response to an increase in PEEP does not necessarily indicate recruitment of atelectatic lung in these patients; other techniques for assessing lung recruitment should be considered [20]. Nevertheless, none of the findings of this study provide any reason to believe that the standard approach to the management of ARDS should be modified for severe COVID-19. Rather, clinicians should continue to follow the accepted evidence-based framework for managing ARDS including COVID-19 ARDS. Unsafe lung stress and strain should be avoided by maintaining lower tidal volumes and driving pressures. Patients with more severe hypoxemia should be ventilated in the prone position, and PEEP should be carefully selected to maintain acceptable 
oxygenation while minimizing overdistention of the baby lung.

In conclusion, until we have evidence to the contrary, we believe that ARDS patients with the same mechani$\mathrm{cal}$ and clinical characteristics should be ventilated in the same way, without regard to whether they have COVID19 ARDS or classical ARDS.

\begin{abstract}
Author details
${ }^{1}$ Interdepartmental Division of Critical Care Medicine, University of Toronto, Toronto, Canada. ${ }^{2}$ Department of Medicine, Division of Respirology, University Health Network, Toronto, Canada. ${ }^{3}$ Toronto General Hospital Research Institute, Toronto, Canada. ${ }^{4}$ Dipartimento di scienze mediche e chirurgiche, Anesthesia and intensive care medicine, Policlinico di Sant'orsola, Alma Mater Studiorum - Università di Bologna, Bologna, Italy. ${ }^{5}$ Keenan Centre for Biomedical Research, Li Ka Shing Knowledge Institute, St. Michael's Hospital, 30 Bond Street, Toronto, ON M5B 1W8, Canada.
\end{abstract}

\section{Compliance with ethical standards}

\section{Conflicts of interest}

ECG reports receiving personal fees and research support in the form of equipment from Getinge and research support in the form of equipment from Timpel. ASS reports receiving personal fees from Baxter and Novalung/Xenios.

\section{Publisher's Note}

Springer Nature remains neutral with regard to jurisdictional claims in published maps and institutional affiliations.

Received: 29 October 2020 Accepted: 3 November 2020

Published online: 25 November 2020

\section{References}

1. Chiumello D, Busana M, Coppola S et al (2020) Physiological and quantitative CT-scan characterization of COVID-19 and typical ARDS: a matched cohort study. Intensive Care Med. https://doi.org/10.1007/s00134-02006281-2

2. Dantzker DR, Brook CJ, Dehart P, Lynch JP, Weg JG (1979) Ventilationperfusion distributions in the adult respiratory distress syndrome. Am Rev Respir Dis 120:1039

3. Pensier J, de Jong A, Hajjej Z et al (2019) Effect of lung recruitment maneuver on oxygenation, physiological parameters and mortality in acute respiratory distress syndrome patients: a systematic review and meta-analysis. Intensive Care Med 45:1691-1702. https://doi.org/10.1007/ s00134-019-05821-9

4. Patel BV, Arachchillage DJ, Ridge CA et al (2020) Pulmonary angiopathy in severe COVID-19: physiologic, imaging, and hematologic observations. Am J Respir Crit Care Med 202:690-699. https://doi.org/10.1164/ rccm.202004-14120C

5. Ackermann M, Verleden SE, Kuehnel M et al (2020) Pulmonary vascular endothelialitis, thrombosis, and angiogenesis in Covid-19. New Eng J Med. https://doi.org/10.1056/NEJMoa2015432
6. Herrmann J, Mori V, Bates JHT, Suki B (2020) Modeling lung perfusion abnormalities to explain early COVID-19 hypoxemia. Nat Commun 11:4883. https://doi.org/10.1038/s41467-020-18672-6

7. Cummings MJ, Baldwin MR, Abrams D et al (2020) Epidemiology, clinical course, and outcomes of critically ill adults with COVID-19 in New York City: a prospective cohort study. The Lancet (British edition) 395:17631770. https://doi.org/10.1016/S0140-6736(20)31189-2

8. Schenck EJ, Hoffman K, Goyal P et al (2020) Respiratory mechanics and gas exchange in COVID-19 associated respiratory failure. Ann Am Thora Soc 17:1158-1161. https://doi.org/10.1513/AnnalsATS.202005-427RL

9. Ferrando C, Suarez-Sipmann F, Mellado-Artigas R et al (2020) Clinical features, ventilatory management, and outcome of ARDS caused by COVID-19 are similar to other causes of ARDS. Intensive Care Med. https ://doi.org/10.1007/s00134-020-06192-2

10. Grasselli G, Tonetti T, Protti A et al (2020) Pathophysiology of COVID-19-associated acute respiratory distress syndrome: a multicentre prospective observational study. Lancet Resp Med. https://doi.org/10.1016/S2213 -2600(20)30370-2

11. Botta M, Tsonas AM, Pillay J et al (2020) Ventilation management and clinical outcome in invasively ventilated COVID-19 patients (PRoVENTCOVID) - a national, multicentre, observational cohort study. Lancet Resp Med. https://doi.org/10.1016/S2213-8

12. Panwar R, Madotto F, Laffey JG, Van Haren FMP (2020) Compliance phenotypes in early ARDS before the COVID-19 pandemic. Am J Respir Crit Care Med. https://doi.org/10.1164/rccm.202005-20460C

13. Horie S, McNicholas B, Rezoagli E et al (2020) Emerging pharmacological therapies for ARDS: COVID-19 and beyond. Intensive Care Med. https:// doi.org/10.1007/s00134-020-06141-z

14. Mauri T, Spinelli E, Scotti E et al (2020) Potential for lung recruitment and ventilation-perfusion mismatch in patients with the acute respiratory distress syndrome from coronavirus disease 2019. Crit Care Med 48:1129-1134. https://doi.org/10.1097/CCM.0000000000004386

15. Pan C, Chen L, Lu C et al (2020) Lung Recruitability in COVID-19-associated acute respiratory distress syndrome: a single-center observational study. Am J Respir Crit Care Med 201:1294-1297. https://doi.org/10.1164/ rccm.202003-0527LE

16. Turbil E, Terzi N, Cour M, Argaud L, Einav S, Guérin C (2020) Positive end-expiratory pressure-induced recruited lung volume measured by volume-pressure curves in acute respiratory distress syndrome: a physiologic systematic review and meta-analysis. Intensive Care Med. https:// doi.org/10.1007/s00134-020-06226-9

17. Sinha P, Delucchi KL, Thompson BT, McAuley DF, Matthay MA, Calfee CS (2018) Latent class analysis of ARDS subphenotypes: a secondary analysis of the statins for acutely injured lungs from sepsis (SAILS) study. Intensive Care Med 44:1859-1869. https://doi.org/10.1007/s00134-018-5378-3

18. Vincent J, Slutsky AS (2020) We have never seen a patient with ARDS. Intensive care Med. https://doi.org/10.1007/s00134-020-06255-4

19. Goligher EC, Kavanagh BP, Rubenfeld GD et al (2014) Oxygenation response to positive end-expiratory pressure predicts mortality in acute respiratory distress syndrome. A secondary analysis of the LOVS and ExPress trials. Am J Respir Crit Care Med 190:70-76. https://doi. org/10.1164/rccm.201404-06880C[doi]

20. Chen L, Del Sorbo L, Grieco DL et al (2020) Potential for lung recruitment estimated by the recruitment-to-inflation ratio in acute respiratory distress syndrome. Clin Am J Respir Crit Care Med 201:178-187. https:// doi.org/10.1164/rccm.201902-0334oc 